\title{
Output Pressure and Pulse-Echo Characteristics of CMUTs as Function of Plate Dimensions
}

Diederichsen, Søren Elmin; Hansen, Jesper Mark Fly; Engholm, Mathias; Jensen, Jørgen Arendt; Thomsen, Erik Vilain

Published in:

2017 IEEE International Ultrasonics Symposium (IUS)

Link to article, DOI:

10.1109/ULTSYM.2017.8092352

Publication date:

2017

Document Version

Peer reviewed version

Link back to DTU Orbit

Citation (APA):

Diederichsen, S. E., Hansen, J. M. F., Engholm, M., Jensen, J. A., \& Thomsen, E. V. (2017). Output Pressure and Pulse-Echo Characteristics of CMUTs as Function of Plate Dimensions. In 2017 IEEE International Ultrasonics Symposium (IUS) IEEE. https://doi.org/10.1109/ULTSYM.2017.8092352

\section{General rights}

Copyright and moral rights for the publications made accessible in the public portal are retained by the authors and/or other copyright owners and it is a condition of accessing publications that users recognise and abide by the legal requirements associated with these rights.

- Users may download and print one copy of any publication from the public portal for the purpose of private study or research.

- You may not further distribute the material or use it for any profit-making activity or commercial gain

- You may freely distribute the URL identifying the publication in the public portal 


\title{
Output Pressure and Pulse-Echo Characteristics of CMUTs as Function of Plate Dimensions
}

\author{
Søren Elmin Diederichsen*, Jesper Mark Fly Hansen*, Mathias Engholm*, Jørgen Arendt Jensen ${ }^{\dagger}$, \\ and Erik Vilain Thomsen* \\ *Department of Micro and Nanotechnology, Technical University of Denmark, DK-2800 Kgs. Lyngby, Denmark \\ ${ }^{\dagger}$ Center for Fast Ultrasound Imaging, Department of Electrical Engineering, Technical University of Denmark, \\ DK-2800 Kgs. Lyngby, Denmark
}

\begin{abstract}
This paper presents an experimental study of the acoustic performance of Capacitive Micromachined Ultrasonic Transducers (CMUTs) as function of plate dimensions. The objective is to increase the output pressure without decreasing the pulse-echo signal. The CMUTs are fabricated with a LOCOS process, followed by direct wafer fusion bonding to a SiliconOn-Insulator (SOI) wafer. In this way, the plate thickness is determined by the SOI wafer device layer thickness, resulting in CMUTs with plate thicknesses of $2,9.3$ and $15 \mu \mathrm{m}$. The corresponding radii and gap heights resulting in an immersion frequency of $5 \mathrm{MHz}$ and a pull-in voltage of $200 \mathrm{~V}$ are obtained using finite element analysis. Hydrophone and plane reflector measurements are used to assess the acoustic performance. Increasing the plate thickness from $2 \mu \mathrm{m}$ to $15 \mu \mathrm{m}$ decreases the pulse-echo bandwidth from $>100 \%$ to $30 \%$. A maximum in both peak-to-peak output pressure and pulse-echo signal is obtained for the $9.3 \mu \mathrm{m}$ plate, which still has a moderate pulseecho bandwidth of $60 \%$. The $9.3 \mu \mathrm{m}$ plate results in a 1.9 times higher peak-to-peak output pressure and a 3.6 times higher pulse-echo signal compared to the $2 \mu \mathrm{m}$ plate. By adjusting the plate dimensions of a CMUT it is possible to optimize its acoustic performance for medical imaging applications, including visualization of deeper structures in the body, as well as nonlinear imaging such as tissue harmonic imaging.
\end{abstract}

\section{INTRODUCTION}

The energy transduction of Capacitive Micromachined Ultrasonic Transducers (CMUTs) relies on the movement of a mechanical component. This commonly comprises a thin flexible plate, which has a low mechanical impedance compared to its bulky lead-based piezoelectric counterpart. As a result, the output pressure of a CMUT is generally lower, thus limiting the imaging penetration depth as well as imaging modalities such as tissue harmonic imaging. However, the CMUT technology offers advantages such as large immersion bandwidth, high receive sensitivity, design flexibility, and integrability with CMOS technology.

For a simple CMUT cell (consisting of a fixed bottom electrode, a dielectric stack and a flexible top electrode), the acoustic performance essentially depends on the following dimensional parameters: The plate thickness, the plate radius/side length, and the effective gap height.

For medical imaging purposes, the operating voltages and frequency of operation impose certain restrictions on the transducer design. The application-specific immersion frequency usually serves as a starting point, as it essentially determines the cell and element dimensions, e.g. the element width is related to the wavelength $\lambda$.

The thickness of the flexible plate typically ranges from submicrons to a few microns [1]-[4], and is in this work predetermined by the SOI wafer device layer thickness. So, provided with both an immersion frequency and a fixed plate thickness, the plate radius remains the only unknown plate parameter. Furthermore, the effective gap height will affect the pull-in voltage, $V_{p i}$, and should therefore be determined based on the desired operating bias and excitation voltages.

Predicting the effect of dimensional scaling of CMUTs can be done in several ways, for instance with lumped element modelling and finite element analysis. Investigations on the influence of plate dimensions on CMUT performance include, but are not limited to [5]-[8]. However, the aim of this paper is to experimentally investigate how the output pressure and pulse-echo signal are affected by the CMUT plate dimensions. In particular, the objective is to increase the output pressure without decreasing the pulse-echo signal.

\section{CMUT DESIGN}

Finite element analysis using the simulation software COMSOL Multiphysics V5.2 (COMSOL AB, Sweden) is used to design CMUTs with an immersion frequency of $5 \mathrm{MHz}$ and a pull-in voltage of $200 \mathrm{~V}$. This is achieved with a full electromechanical-acoustic model, where the plate thickness is fixed and the circular cell radius and gap height are varied until the desired immersion frequency and pull-voltage are reached. This is performed by running COMSOL with MATLAB (MathWorks, Inc., Natick, MA, USA).

For the purpose of obtaining clearly measurable signals during the characterization, the element width and element height is set to $900 \mu \mathrm{m}$ and $6 \mathrm{~mm}$, respectively. The circular cells are packed in a hexagonal closed-packed pattern with an inter-cell distance of $5 \mu \mathrm{m}$ to ensure sufficiently bonding area. Three different CMUT designs are realized according to the available SOI wafers. In specific, CMUTs with plate thicknesses of 2, 9.3 and $15 \mu \mathrm{m}$ are fabricated. Table I shows the design dimensions for the three designs. As a result of the different radii, the fill factors of the CMUT layouts varies. The active cell part of each element of the 2, 9.3 and $15 \mu \mathrm{m}$ designs amount to $73.3 \%, 79.6 \%$ and $74.6 \%$, respectively. 
TABLE I

CMUT Cell Design Parameters

\begin{tabular}{|c|c|c|}
\hline Plate thickness $[\mu \mathrm{m}]$ & Plate radius $[\mu \mathrm{m}]$ & Gap height $[\mathrm{nm}]$ \\
\hline 2 & 24.5 & 246 \\
\hline 9.3 & 60 & 151 \\
\hline 15 & 75 & 128 \\
\hline
\end{tabular}

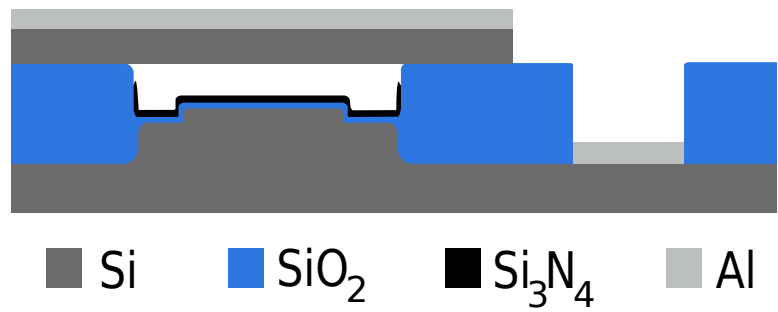

Fig. 1. Cross-section of a CMUT made with a LOCOS process and direct wafer fusion bonding. For simplicity only one cell is shown. The illustration is not to scale.

\section{CMUT FABRICATION AND EXPERIMENTAL SETUP}

The CMUTs are fabricated using two LOCal Oxidation of Silicon (LOCOS) processes in combination with a direct wafer bonding method, similar to the procedure first presented in [1].

In this work, the fabrication process involves four lithographic masks. A highly doped silicon wafer with a resistivity of $<0.025 \Omega \mathrm{cm}$ is thermally oxidized at $1100^{\circ} \mathrm{C}$ under dry conditions to achieve a $\mathrm{SiO}_{2}$ layer thickness of $100 \mathrm{~nm}$, followed by deposition of both stoichiometric $\mathrm{Si}_{3} \mathrm{~N}_{4}$ and polycrystalline silicon layers (both with a thickness of $100 \mathrm{~nm}$ ). Patterns are then etched into these layers. After a wet oxidation at $1100^{\circ} \mathrm{C}$ all layers are stripped, leaving only silicon bumps (as different gaps are desired, different oxidation times and thus silicon bumps are needed). The bump radius corresponds to two-thirds of the cell radius.

This procedure is partly repeated, only this time the insulating layers are not stripped and the resulting $\mathrm{SiO}_{2}$ and $\mathrm{Si}_{3} \mathrm{~N}_{4}$ layer thicknesses are $350 \mathrm{~nm}$ and $100 \mathrm{~nm}$, respectively. A final thermal wet oxidation at $1100{ }^{\circ} \mathrm{C}$ serves to form the cell cavities. A SOI wafer is bonded together with the cavity wafer using direct wafer fusion bonding. After removing the SOI wafer handle layer and buried oxide layer, trenches are etched to access the bottom substrate. The process is finalized by depositing and patterning $400 \mathrm{~nm}$ aluminum for the top and bottom electrodes. A cross-sectional view of such CMUT is shown in Fig. 1. The measured dimensions for the three CMUT designs are listed in Table II.

TABLE II

MEASURED VERTICAL CMUT DIMENSIONS

\begin{tabular}{|c|c|c|}
\hline Plate thickness $[\mu \mathrm{m}]$ & Bump height $[\mathrm{nm}]$ & Gap height $[\mathrm{nm}]$ \\
\hline 2 & 389 & 255 \\
\hline 9.3 & 453 & 154 \\
\hline 15 & 480 & 135 \\
\hline
\end{tabular}

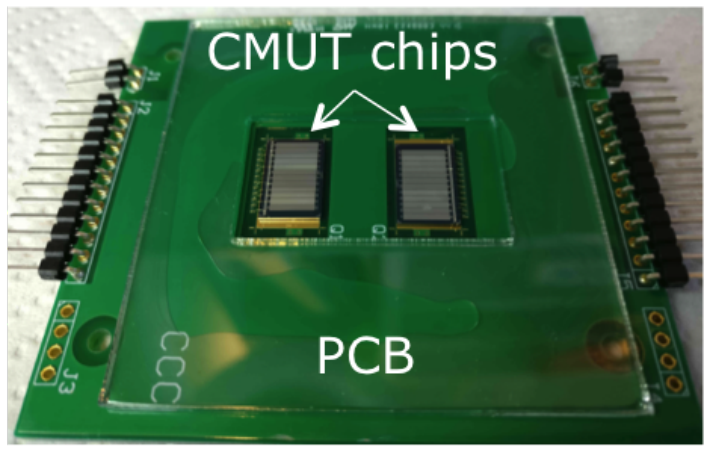

Fig. 2. Photo of two CMUTs mounted on a PCB. In a later preparation step a flat PDMS layer of approx. $2 \mathrm{~mm}$ will cover the CMUT top electrodes and wire-bonds.

Wafers with 54 chips, each containing twelve elements are fabricated. After dicing, the CMUT chips are mounted on printed circuit boards (PCBs) with wire-bonds ensuring electrical connection between the chip and the PCB. A photo of such mounted CMUTs is shown on Fig. 2. To measure in water, an acrylic glass (PMMA) dam is glued onto the PCB and filled with a flat polydimethylsiloxane (PDMS) coating of a thickness of approx. $2 \mathrm{~mm}$. The coating procedure is similar to the one described in [9]. Furthermore, during measurements a cylindrical PMMA holder pressing down on a rubber ring placed on top of the PCB serves as a water tank.

\section{CMUT CHIP CHARACTERIZATION}

The PCB-mounted CMUTs are placed in front of either a hydrophone or a plane reflector. These are placed at a distance of $1 \mathrm{~cm}$ from the CMUT surface and aligned using an XY stage. The hydrophone and plane reflector measurements are carried out with a 2410 Keithley Sourcemeter to provide a DC voltage, while a Tektronix AGF3102C arbitrary function generator provides a pulse excitation voltage of $\pm 10 \mathrm{~V}$. The relatively low $\mathrm{AC}$ voltage is chosen to maintain the receiver in the small signal linear mode. A photo of the measurement setup is shown in Fig. 3.

The two-way time responses are measured by pulsing with a 16-period square wave at discrete frequencies, while recording the pulse-echo signals with an AD8332 variable gain receive amplifier (with $V_{\text {gain }}=0.2 \mathrm{~V}$ ) connected to a digital oscilloscope. From this, the maximum peak-to-peak pulse-echo signals, center frequencies, and fractional bandwidths are obtained. The bias voltage used for the pulseecho measurements is the positive voltage polarity (having a positive potential on the CMUT top electrode/plate relative to an electrically grounded bottom substrate) corresponding to $80 \%$ of the respective pull-in voltage.

The transmit pressure waves are recorded with a digital oscilloscope using a calibrated ONDA HGL-0400 hydrophone connected to an AC-2010 pre-amplifier (Onda Corporation, CA, USA). The peak-to-peak pressures are obtained from a two-period, bipolar, square pulse at the respective center frequencies. 


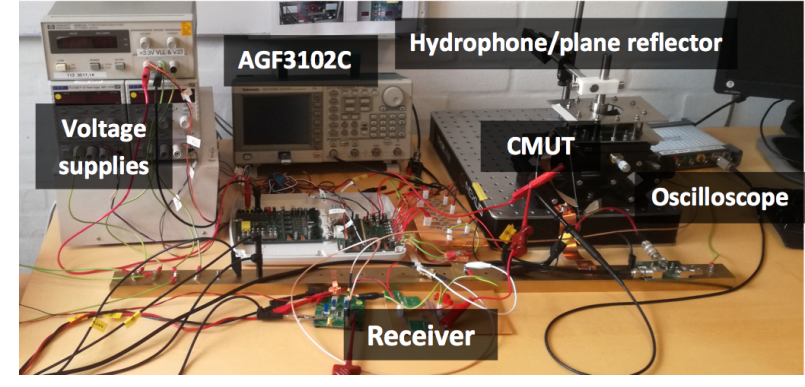

Fig. 3. Photo of the hydrophone/plane reflector measurement setup.

\section{Results and Discussion: Acoustic Performance}

\section{A. Hydrophone and Plane Reflector Measurements}

Fig. 4 shows the measured peak-to-peak pulse-echo signal as function of frequency for the three plate thicknesses. The center frequencies are $5,5.5$ and $6 \mathrm{MHz}$ for a plate thickness of 2, 9.3 and $15 \mu \mathrm{m}$, respectively. These results are also shown in Table III, together with the measured pull-in voltages, peakto-peak output pressures, maximum peak-to-peak pulse-echo signals and $-6 \mathrm{~dB}$ pulse-echo fractional bandwidths for the three CMUT designs.

The measured hydrophone signals at the respective center frequencies are shown in Fig. 5. Notice that the three CMUTs are operated at $90 \%$ of their pull-in voltage, and furthermore that the $9.3 \mu \mathrm{m}$ plate is biased with a negative voltage, whereas the other two have a positive voltage bias. This is merely to show how the signal becomes mirrored around the first axis when changing the polarity of the voltage bias. However, the signal amplitude in this polarity is, as expected, higher than for a positive polarity. In the comparison, all the transmit signals are obtained at a positive bias voltage polarity at $80 \%$ of the pull-in voltage, and the results are listed in Table III.

Nevertheless, the purpose of showing these three plots is to show that the pulse length increases with increasing plate thickness, which is also the case for the pulse-echo measurements. Consequently, the bandwidth decreases with increasing plate thickness. This is not surprising, as the plate inertia and stiffness are expected to increase with increasing plate thickness.

To sum up the measurement results, referring to Table III, the highest peak-to-peak output pressure of $380 \mathrm{kPa}$ (at $0.8 V_{p i}$ ) is obtained for the $9.3 \mu \mathrm{m}$ plate. In fact, an maximum in both peak-to-peak output pressure and pulse-echo signal is seen for the $9.3 \mu \mathrm{m}$ plate, which still has a moderate pulse-echo bandwidth of $60 \%$. The $9.3 \mu \mathrm{m}$ plate results in a 1.9 times higher peak-to-peak output pressure and a 3.6 times higher pulse-echo signal compared to the $2 \mu \mathrm{m}$ plate. On the other hand, the highest pulse-echo bandwidth is observed for the $2 \mu \mathrm{m}$ plate.

Several factors affect the acoustic performance of a CMUT. For instance, in this study the ratio of medium loading to mechanical impedance is different for the three designs and will therefore affect the oscillation conditions differently. Another difference is the radiation impedance from neighbouring

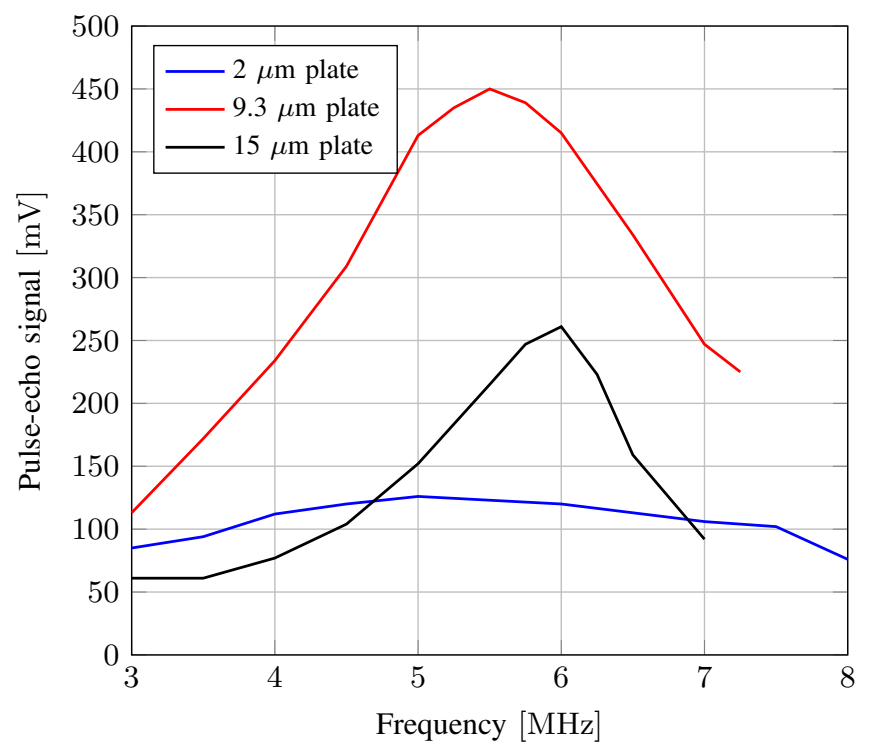

Fig. 4. Peak-to-peak pulse-echo signal as function of frequency for CMUTs with plate thicknesses of $2,9.3$ and $15 \mu \mathrm{m}$, respectively. The CMUTs are operated at $80 \%$ of their respective pull-in voltage and excited with a $\pm 10 \mathrm{~V}$ bipolar, square pulse. The spectra are obtained by recording the peak-to-peak amplitude of a 16-period pulsing signal at discrete frequencies.

TABLE III

MEASURED DATA OF THE ACOUSTIC PERFORMANCE OF CMUTS WITH DIFFERENT PLATE THICKNESSES. THE CMUTS ARE BIASED WITH A POSITIVE VOLTAGE POLARITY. THE DISTANCE BETWEEN THE CMUT SURFACE AND EITHER HYDROPHONE OR PLANE REFLECTOR IS $1 \mathrm{CM}$.

\begin{tabular}{|l|c|c|c|c|c|}
\hline $\begin{array}{l}\text { Plate } \\
\text { thickness } \\
{[\mu \mathrm{m}]}\end{array}$ & $\begin{array}{c}\text { Pull-in } \\
\text { voltage, } V_{p i} \\
{[\mathbf{V}]}\end{array}$ & $\begin{array}{c}\text { Center } \\
\text { frequency } \\
{[\mathbf{M H z}]}\end{array}$ & $\begin{array}{c}\text { Peak-to-peak } \\
\text { output pressure } \\
\text { at } \mathbf{0 . 8} V_{p i} \\
{[\mathbf{k P a}]}\end{array}$ & $\begin{array}{c}\text { Peak-to-peak } \\
\text { pulse-echo } \\
\text { signal } \\
\text { at } \mathbf{0 . 8} V_{p i} \\
{[\mathbf{m V}]}\end{array}$ & $\begin{array}{c}\text { Pulse-echo } \\
\mathbf{- 6} \mathbf{d B} \\
\text { fractional } \\
\text { bandwidth } \\
\text { in \% }\end{array}$ \\
\hline 2 & 210 & 5 & 203 & 126 & $>100$ \\
\hline 9.3 & 200 & 5.5 & 380 & 450 & 60 \\
\hline 15 & 200 & 6 & 238 & 261 & 30 \\
\hline
\end{tabular}

cells and hence overall damping, which depends on the cell dimensions and intra-element cell arrangement. Also, the fill factor and support oxide thickness will directly influence the parasitics of the devices. Furthermore, the CMUTs in this work are designed to have the same immersion frequency and pull-in voltage, which is realized by adjusting radii and gap heights. The reasoning being that the CMUTs should be operated as close to the same absolute voltages as possible is to imitate real ultrasound scanner conditions. Nevertheless, the gap height influences both the output pressure and sensitivity. Operating the CMUTs with other excitation signals of different shapes and/or number of periods will naturally affect the transmit bandwidth. However, under these particular hydrophone measurement conditions it is the nature of the excitation signal that limits the transmit bandwidth. 

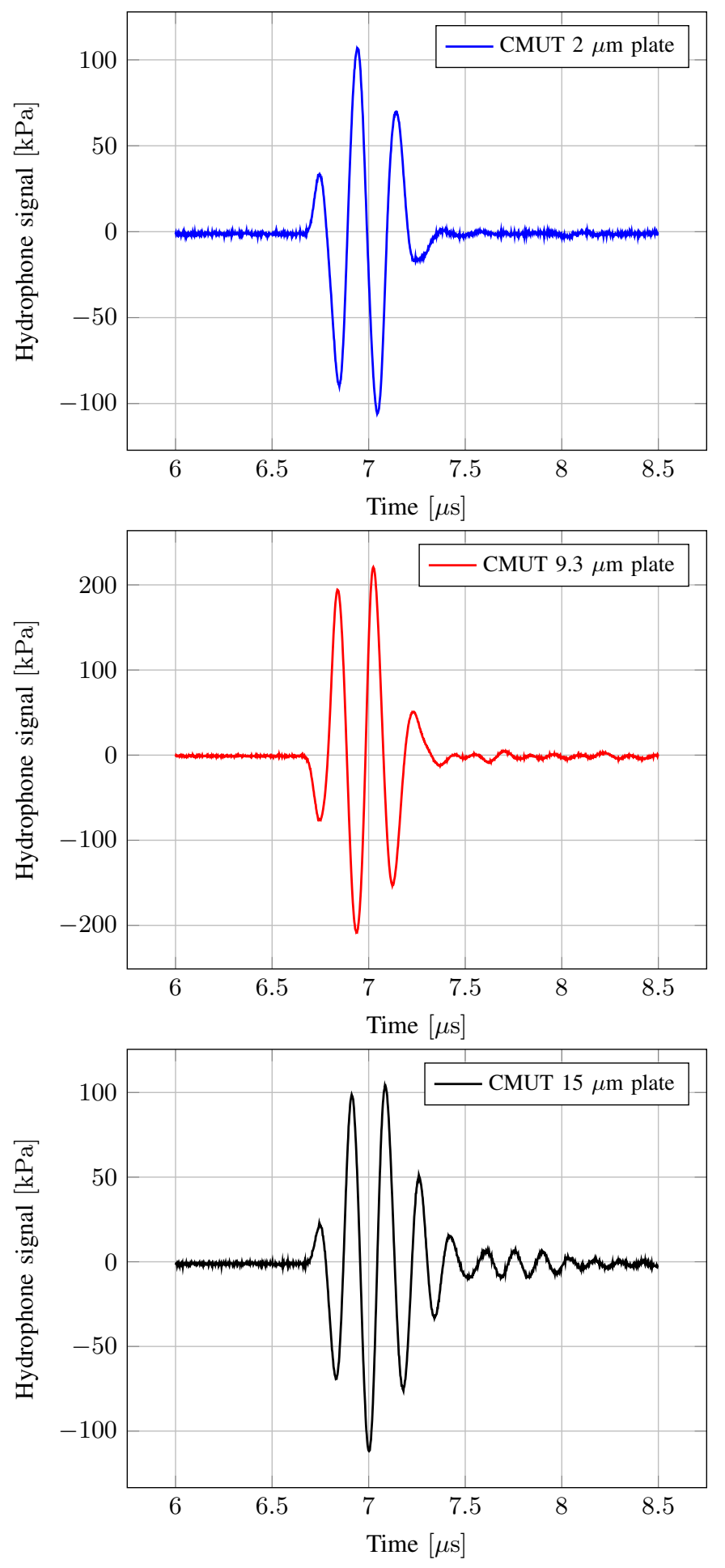

Fig. 5. The three plots show the hydrophone signal versus time for CMUTs with plate thicknesses of $2,9.3$ and $15 \mu \mathrm{m}$ and biased with positive, negative and positive voltage polarity, respectively. All CMUTs are biased at $90 \%$ of the pull-in voltage and excited with a $\pm 10 \mathrm{~V}$, two-period, bipolar, square pulse.

\section{CONCLUSION}

The acoustic performance of CMUTs with different plate dimensions was investigated for plate thicknesses of 2, 9.3, and $15 \mu \mathrm{m}$. The CMUTs were designed with finite element analysis to have an immersion center frequency of $5 \mathrm{MHz}$ and a pull-in voltage of $200 \mathrm{~V}$. They were successfully fabricated using two consecutive LOCOS processes in combination with a direct wafer fusion bonding process. The CMUTs were mounted on PCBs, wire-bonded and coated with a polymer for measurements in immersion. The performance of the three designs was assessed with both hydrophone and plane reflector measurements. This study shows that the highest output pressure and pulse-echo signal is achieved for the $9.3 \mu \mathrm{m}$ plate. More generally, this experimental study has shown that customizing the plate dimensions can be used to adjust the acoustic performance within the framework of a specific transducer application.

\section{ACKNOWLEDGEMENT}

This work is financially supported by the Danish National Advanced Technology Foundation (82-2012-4) and by BK Ultrasound, Herlev, Denmark.

\section{REFERENCES}

[1] K. Park, H. Lee, M. Kupnik, O. Oralkan, and B. Khuri-Yakub, "Fabricating capacitive micromachined ultrasonic transducers with direct waferbonding and locos technology," in Micro Electro Mechanical Systems. IEEE 21st International Conference on MEMS. IEEE, 2008, pp. 339342.

[2] Y. Huang, A. S. Ergun, E. Hæggström, M. H. Badi, and B. T. KhuriYakub, "Fabricating capacitive micromachined ultrasonic transducers with wafer-bonding technology," J. Microelectromech. Syst, vol. 12, no. 2, pp. 128-137, 2003.

[3] T. L. Christiansen, M. F. Rasmussen, J. P. Bagge, L. N. Moesner, J. A. Jensen, and E. V. Thomsen, "3-D imaging using row-column-addressed arrays with integrated apodization - part ii: transducer fabrication and experimental results," IEEE Transactions on Ultrasonics, Ferroelectrics, and Frequency Control, vol. 62, no. 5, pp. 959-971, May 2015.

[4] A. Lei, S. E. Diederichsen, S. M. Hansen, M. B. Stuart, J. P. Bagge, J. A. Jensen, and E. V. Thomsen, "Elimination of second-harmonics in cmuts using square pulse excitation," in Ultrasonics Symposium (IUS), 2016 IEEE International. IEEE, 2016, pp. 1-4.

[5] G. G. Yaralioglu, S. Ergun, and B. T. Khuri-Yakub, "Finite-element analysis of capacitive micromachined ultrasonic transducers," IEEE transactions on ultrasonics, ferroelectrics, and frequency control, vol. 52, no. 12, pp. 2185-2198, 2005.

[6] B. Khuri-Yakub, G. Yaralioglu, and B. Bayram, "Finite element analysis of CMUTs: Conventional vs. collapse operation modes," in Ultrasonics Symposium, 2006. IEEE. IEEE, 2006, pp. 586-589.

[7] A. Lei, S. E. Diederichsen, M. F. la Cour, M. B. Stuart, T. L. Christiansen, J. A. Jensen, and E. V. Thomsen, "Dimensional scaling for optimized CMUT operations," in 2014 IEEE International Ultrasonics Symposium, Sept 2014, pp. 2595-2598.

[8] M. Engholm, A. Tweedie, J. Jensen, G. Harvey, S. E. Diederichsen, J. A. Jensen, and E. V. Thomsen, "Simulating CMUT arrays using time domain FEA," in Ultrasonics Symposium, 2017. IEEE. IEEE, 2017.

[9] M. F. la Cour, M. B. Stuart, M. B. Laursen, S. E. Diederichsen, E. V. Thomsen, and J. A. Jensen, "Investigation of PDMS as coating on CMUTs for imaging," in Proc. IEEE Ultrason. Symp., 2014, pp. 2584-2587. 